\title{
Phenols from Pyrolysis and Co-Pyrolysis of Tobacco Biomass \\ Components
}

\author{
Joshua K. Kibet ${ }^{1}$, Lavrent Khachatryan*², and Barry Dellinger ${ }^{2}$ \\ ${ }^{1}$ Department of Chemistry, Egerton University, P.O. Box 536, Egerton, Kenya \\ ${ }^{2}$ Department of Chemistry, Louisiana State University, Baton Rouge, LA, 70803, USA \\ *E-mail: $\underline{\text { khach1@1su.edu }}$ Tel. +1225 5784417
}

\begin{abstract}
\end{abstract}
Phenol and its derivatives (phenol, $o-, m-, p$-cresols, catechol, hydroquinone, methoxy substituted phenols etc. referred to as phenolic compounds or phenols) are well-known toxicants that exist in the environment and affect both human and natural ecosystems. This study explores, quantitatively, the yields of phenolic compounds from the thermal degradation (pyrolysis and oxidative pyrolysis) of common tobacco biomass components (lignin, tyrosine, ethyl cellulose, sodium alginate, and laminarin) as well as some mixtures (lignin/tyrosine, ethyl cellulose/tyrosine, sodium alginate/tyrosine) considered important in high temperature cooking, tobacco smoking, and forest fires. Special attention has been given to binary mixtures including those containing tyrosine -pyrolysis of binary mixtures of tyrosine with lignin and ethyl cellulose results in significant reductions in the yields of majority phenols relative to those of tyrosine. These results imply that the significant reductions of phenol yields in mixtures are not only dependent upon the mass fractions of the components but also the synergetic inhibition effect of biomass components on the thermal degradation of tyrosine. A mechanistic description of this phenomenon is suggested. The results may also be implied in tobacco industry that the cigarette paper (as ethyl cellulose derivative) may play a critical role in reducing the concentration of phenolic compounds released during tobacco burning.

Key Words: fractional pyrolysis/oxidative pyrolysis, tyrosine, lignin, ethyl cellulose, inhibition 


\section{Introduction}

Various scientific and epidemiological studies have explicitly demonstrated that cigarette

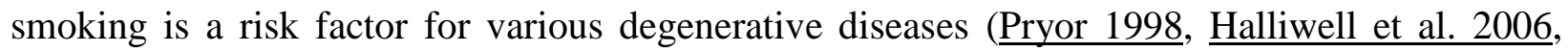

31 Ghosh et al. 2012). Molecular phenolic compounds such as phenol, $p$-cresol, $o$-cresol, $m$-cresol, 32 catechol, hydroquinone, and methoxy-substituted phenols are well-known threats to both 33 environmental ecosystems as well as biological systems. Phenolic compounds found in cigarette 34 smoke considered toxic are those believed to originate from the thermal degradation of lignin; 35 one of the major components of tobacco (Smith and Hansch 2000). These phenols include 436 vinyl phenol, 4-vinyl guaiacol, syringol and vanillin (D. Selassie et al. 1999, $\underline{\text { Smith and Hansch }}$

$37 \underline{2000})($ Kibet et al. 2012). Substituted phenols bearing electron-donating substituents would 38 therefore be expected to be more toxic (Smith and Hansch 2000)(Kibet et al. 2013). For instance, 39 phenol affects liver enzymes, lungs, kidneys, and the cardiovascular system, while $m$-cresol 40 attacks the nervous systems (Talhout et al. 2011). Phenoxy radicals produced from further 41 degradation of phenol(Khachatryan 2008), on the other hand can combine to form dibenzo-p42 dioxin/dibenzofuran $(\mathrm{DD} / \mathrm{F})$ which is one of the most toxic environmental pollutants (Berho and 43 Lesclaux 1997, Wiater et al. 2000, Khachatryan 2003, Evans and Dellinger 2005). The p44 hydroxyl phenoxy radical known in literature as neutral semi-quinone radical has been reported 45 in cigarette smoke and shown to be highly active in generation of reactive oxygen species (ROS) 46 in biological systems (Pryor et al. 1998, Dellinger et al. 2000). ROS induces oxidative stress in 47 living organisms which is currently considered a sure cause of health problems (Dellinger et al. 48 2001, Squadrito et al. 2001, Hirakawa et al. 2002, Maskos et al. 2005, Cormier et al. 2006). Once 49 in the biological environment, phenols can be converted to quinones (Bolton et al. 2000). 50 Quinones are a class of toxicological intermediates which are believed to create a variety of 
51 hazardous effects in vivo including acute cytotoxicity, immunotoxicity, and carcinogenesis

52 (Bolton et al. 2000).(DeCaprio 1999, Hirakawa et al. 2002). Quinones are highly redox active

53 compounds which redox cycle with their respective semi-quinone radicals, resulting in the

54 formation of reactive oxygen species.High yields of phenol have been detected from fractional

55 pyrolysis / oxidative pyrolysis of tyrosine (one of the tobacco biomass components) reported

56 from our laboratory (Kibet et al. 2013). Nevertheless, determining the toxicity of tobacco

57 chemicals in general from available literature may not be an exact procedure but rather an

58 estimation (Smith and Hansch 2000).

59 The quantitation of phenols (Wt\% yield) from the pyrolysis and co-pyrolysis of biomass

60

61

62

63

64

65

66

67

68

69

70

71

72

73

materials are critical towards understanding their evolution with temperature. This information is important in food processing, tobacco burning and other industries such as confectioneries. It would thus imply processing foods at certain optimum temperatures will be beneficial and minimize the formation of high yields of poisonous reaction by-products.

Accordingly, this study will explore in detail the formation of biologically important phenols such as phenol, $p$-cresol, $o$-cresol, $m$-cresol, catechol, hydroquinone, and methoxysubstituted phenols from selected tobacco biomass materials (lignin, tyrosine, ethyl cellulose, sodium alginate and laminarin - Fig. 1) and equimolar mass fractions of some mixtures such as lignin/tyrosine, cellulose/tyrosine, and alginate/tyrosine under various pyrolysis conditions. To the best of our knowledge, very few studies have been conducted on the co-pyrolysis of biopolymeric mixtures presented in this work.

Special attention has been given to binary mixtures especially those containing tyrosine.

It has been postulated that the combined study of biomass and amino acids is the best approach to grasp a more comprehensive mechanism of nitrogen chemistry in biomass components $(\mathrm{N}$ - 
74 Chemistry) (Becidan et al. 2007). While the pyrolysis of amino acids has been extensively

75 studied, there is very little information on the product distribution from the co-pyrolysis of amino

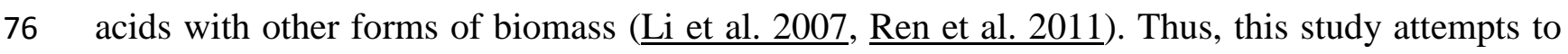

77 bridge this gap in a more detailed manner. Since most of the elemental nitrogen is bound in

78 proteins, co-pyrolysis of lignin + tyrosine, ethyl cellulose + tyrosine, and sodium alginate +

79 tyrosine was conducted with the aim of finding features that are protein-specific ( $\mathrm{Li}$ et al.

80 2007):(Hansson et al. 2003, Hansson et al. 2004). Notably, the studies of the pyrolysis of some

81 biomass constituents such as tyrosine, laminarin and sodium alginate are scarce in literature. This

82 investigation primarily focuses on the formation of phenolic compounds from a broad range of

83 biopolymers and selected mixtures.

\section{2. Materials and Methods}

2.1. Materials. The biomass samples; lignin, tyrosine, ethyl cellulose, sodium alginate and laminarin ( $\geq 99.99 \%$, purity) explored in this study were purchased from sigma Aldrich Inc.

87 (USA) and used without further treatment. The lignin used in this study was hydrolytic, described in our earlier article (Kibet et al. 2012).

2.2. The system for thermal diagnostic studies (STDS). In order to avoid many experimental challenges associated with analysis of biomass pyrolysis (Chiavari et al. 2001), the system for thermal diagnostic studies (STDS) (Rubey and Grant 1988) was used in this work

92 (SFig.1- Supplementary material), vide infra. The sampling of the reactor pyrolysate was done at the head of a GC column at $-60{ }^{\circ} \mathrm{C}$ using an in-line GC-MS. The experimental details for STDS 94 are reported elsewhere (Rubey and Grant 1988, Evans and Dellinger 2005)(Kibet et al. 2012). It 95 is a well-established technique for analysis of a wide range of organic materials including amino 96 acids (Lawrence J. Marnett and Wilcox 1988). 

technique applied in this study is an experimental procedure in which the same sample is continuously pyrolyzed at each pyrolysis temperature (Kibet et al. 2012)(Agblevor et al. 2010, Kibet et al. 2013). It is defined as a selective, in situ conversion of biopolymers to products

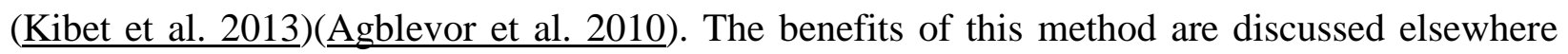
(Kibet et al. 2012)( Kibet et al. 2013).

The thermal degradation of biomass components was generally investigated in a tubular flow reactor over the temperature range of $200{ }^{\circ} \mathrm{C}$ to $800{ }^{\circ} \mathrm{C}$ at 1 atmospheric pressure, typically 105 in $50{ }^{\circ} \mathrm{C}$ increments under two reaction conditions; pyrolysis in $\mathrm{N}_{2}$ and oxidative pyrolysis in $4 \%$ $\mathrm{O}_{2}$ in $\mathrm{N}_{2}$ (SFig.1). The concentration of oxygen in the oxidative pyrolysis experiments was kept low to optimize the formation of phenolic products (Kibet et al. 2013). The gas flow rate was designed to maintain a constant residence time of $0.2 \mathrm{~s}$. The sample, $30 \pm 0.2 \mathrm{mg}$, was loaded into a tubular quartz reactor $(0.3 \mathrm{~cm}$ i.d. x $17.7 \mathrm{~cm}$, volume $1.25 \mathrm{~mL})$ and held in place by quartz wool to avoid being swept by carrier gas flowing through the reactor. The reactor used in this work is presented in SFig. 2. A summary flow chart outlining the steps taken during the 112 determination of phenolic compounds from the thermolysis of bio-polymers is presented in SFig. 3. For co-pyrolysis experiments, equimolar mixtures of biopolymer/tyrosine were pyrolyzed in a 114 reactor placed inside an electrically heated furnace whose heating rate was $10{ }^{\circ} \mathrm{C} \mathrm{s}^{-1}$ (SFig.1). 115 After a total pyrolysis time of 3 minutes, the furnace was turned off and the sample cooled in 116 flowing $\mathrm{N}_{2}$ while exposing the reactor to a cooling fan (Kibet et al. 2012). The residence time 117 with charred material was short enough ( 0.2 seconds $)$ to minimize secondary reactions. spectrometry (GC-MS) analysis of the pyrolysate was conducted using an Agilent 6890N gas 
120 chromatograph equipped with a 5973N mass selective detector (MSD) with an electron impact

121 (EI) ion source set at $70 \mathrm{eV}$. A DB5-MS GC column $(30 \mathrm{~m} \times 0.25 \mathrm{~mm} \times 0.25 \mu \mathrm{m})$ was used (Kibet

122 et al. 2012), SFig.1. The temperature program was typically: - $60{ }^{\circ} \mathrm{C}$ initial temperature; held for

$1233 \mathrm{~min}$ followed by heating at a rate of $15{ }^{\circ} \mathrm{C} / \mathrm{min}$ to $130{ }^{\circ} \mathrm{C}$; held for 1 minute at this temperature

124 and heated to $300{ }^{\circ} \mathrm{C}$ at a heating rate of $25{ }^{\circ} \mathrm{C} / \mathrm{min}$ (final temperature; held for 5 min). The

125 injector and MSD detector temperatures were $250{ }^{\circ} \mathrm{C}$ and $280{ }^{\circ} \mathrm{C}$, respectively. Ultra high pure

126 (UHP, 99.999\%) helium was used as the carrier gas at constant flow of 3.3mL/min. The mass

127 spectrometer was operated in total ion current mode (TIC) over a mass scan range of $15-600$

128 amu. As discussed elsewhere (Kibet et al. 20123), the pyrolysis products (phenols) were

129 determined using NIST library and by comparing retention times with those of pure compounds

130 (standards). The experimental data presented in this study were averaged values from 2 or more

131 replicates.

\subsection{Calibration of Pyrolysis Products}

133 A stock solution was prepared by weighing $0.1 \mathrm{~g}$ of each individual calibration compound and 134 dissolved in a10 mL volumetric flask containing analytical grade methanol. Aliquots of the 10 $135000 \mu \mathrm{g} / \mathrm{mL}$ stock solution was then diluted to concentrations of $100,500,800,1000,1200$, and $1361500 \mu \mathrm{g} / \mathrm{mL}$. $1 \mu \mathrm{L}$ was injected into the GC-MS and the peak area of each standard compound 137 was then plotted against the mass of the compound in $\mu \mathrm{g} / \mathrm{mL}$ solution and then linearly regressed 138 to obtain the calibration curve of the compound. The $\mathrm{R}^{2}$ value was greater than 0.98 for all 139 standards. The weight percent yield of each compound was determined using the following 140 formula:

$$
Y=\left(\frac{\text { weight of product }, w}{\text { weight of sample }, W}\right) \times 100
$$


142 where $\mathrm{Y}$ is the yield of the pyrolysis product in $\mathrm{Wt} \%$.

143 The structural formulas of major products (phenols) and their weight \% yields from the thermal

144 degradation of tobacco components; lignin and tyrosine are presented in the supplemental

145 information (Table S1, and Table S2 - Table S6, respectively).

\section{3. Results and Discussion}

\section{3.1. Pyrolysis of lignin and co-pyrolysis of lignin/tyrosine mixtures}

148 The quantitative release of common phenolic compounds from pyrolysis and co-pyrolysis of 149 lignin and tyrosine was investigated experimentally and presented in Fig. 2. It was clear that 150 some phenolic products overlapped while others were not detected under certain pyrolysis 151 conditions. For instance, hydroquinone was detected only under oxidative conditions when lignin 152 and tyrosine were co-pyrolyzed. The char yields (Fig. 2) decreased with increase in pyrolysis 153 temperature. Interestingly, above $500{ }^{\circ} \mathrm{C}$, the char yields and pyrolysis products decreased in a 154 similar trend. This is because, above this region $\left(500{ }^{\circ} \mathrm{C}\right)$ most of the pyrolysis products would 155 be gaseous, mainly $\mathrm{CO}, \mathrm{CO}_{2}$, methane, and other small molecules including $\mathrm{H}_{2}$.

From Fig. 3, it is evident that most phenolic compounds decreased during the co-

157 pyrolysis of lignin and tyrosine compared to when tyrosine was pyrolyzed individually. For 158 instance, phenol was decreased by nearly 30\% during the co-pyrolysis of lignin and tyrosine 159 (Fig. 3A) while for oxidative pyrolysis phenol decreased by about 25\% (Fig. 3B). Majority of 160 observed reaction products were methoxy substituted phenols: syringol, guaiacol, and 3-methoxy 161 catechol. Other major phenols observed in this study were phenol, $p$-cresol, catechol, 4-ethyl 162 phenol, 4-vinyl guaiacol, and eugenol. Pyrolysis of tyrosine generally gave rise to higher levels 163 of phenol and $p$-cresol relative to that from the thermal degradation of lignin (Fig. 3). 

phenolic compounds especially phenol, $p$-cresol and $o$-cresol. However, the pyrolysis/oxidative pyrolysis of binary mixtures of lignin and tyrosine results in significant reduction in the yields of

167 some phenols relative to those of tyrosine, Fig. 3A (vide infra, Table 1).

\subsection{Pyrolysis of ethyl cellulose, and ethyl cellulose/tyrosine mixture.}

Ethyl cellulose (EC) is a semi-synthetic cellulose derivative that has found widespread application in the food and cigarette paper industries (Guo and Gray 1994, Lai et al. 2010). The

171 chemical structure of EC comprises chains of anhydroglucose units linked together by oxygen 172 bridges, with the most commonly used materials having a degree of ethoxyl substitution between 17343 and $50 \%$ (Lai et al. 2010). The ethyl cellulose used in this study had an ethoxy substitution of $17448 \%$. The co-pyrolysis of ethyl cellulose with tyrosine resulted in lower yields of phenolic 175 products in comparison with the yields observed when tyrosine was co-pyrolyzed with lignin or 176 when tyrosine was pyrolyzed individually, Fig. 4. However, it should be noted that during 177 individual pyrolysis of tyrosine $30 \pm 2 \mathrm{mg}$ was used while for co-pyrolysis experiments equimolar 178 quantities of sample was used i.e. $15 \mathrm{mg} / 15 \mathrm{mg}$. As a result, phenol was decreased by $83 \%$ 179 while $p$-cresol was decreased by $87 \%$ in comparison with experiments in which pure tyrosine was pyrolyzed. During oxidative co-pyrolytic experiments, phenol was decreased by $96 \%$ while $181 p$-cresol was decreased by $94 \%$. Co-pyrolysis of tyrosine with ethyl cellulose yielded neither 182 catechol nor hydroquinone, Table 1. A similar observation was noted when tyrosine was co183 pyrolyzed with lignin. mixture. 
It is evident from Table S7 (supplementary information) that the co-pyrolysis of sodium

alginate and tyrosine in a nitrogen atmosphere does not yield phenols at all, although some phenolic compounds were detected from sodium alginate pyrolysis. Laminarin being a minor component of tobacco (Rioux et al. 2007, Anastasakis et al. 2011) was not considered for copyrolytic experiments with tyrosine. Nonetheless, lower amounts of common phenols (phenol, $p$ cresol, $o$-cresol) were observed from laminarin pyrolysis (oxidative pyrolysis did not yield any phenols).

\subsection{Mechanistic explanation for the drastic reduction of phenol yields from co-} pyrolysis/co-oxidation of biopolymer/tyrosine mixtures.

The co-pyrolysis experiments show large decrease in yields of phenols in comparison to the yields observed from tyrosine pyrolysis, Table 1, Fig. 4. For instance, the total yields of three major phenols from Table 1 (phenol, $p$ - and $o$ - cresols) depends differently upon mass fraction of biopolymer/tyrosine mixture (components' ratio $=1: 1)$ i.e. at twice dilution of tyrosine by lignin or ethyl cellulose the total yields of phenol $+p$-cresol $+o$-cresolfrom tyrosine pyrolysis $(\sim 61 \%)$ drops almost twice in case of Lig/Tyr pyrolysis (28.2\%) while it drops by a factor of $\sim 5$ during EC/Tyr pyrolysis $(12.36 \%)$. A drastic drop of the yields of the mentioned phenols also occurred during oxidative pyrolysis of Lig/Tyr (by a factor of 2.4) and EC/Tyr (by a factor 15), Table 1. To examine more clearly the dilution effect on the reduction of the yields of phenolic compounds (phenol, $p$-cresol, and $o$-cresol), a multi-component mixture (at different mass fraction) pyrolysis was performed.

\subsubsection{The Co-Pyrolysis of Lignin, Cellulose, Pectin, Tyrosine, and Glutamic Acid Mixture}

A mixture of five tobacco components (Lig: EC : Pectin : Tyr : Glutamic acid) were pyrolyzed in a tubular flow reactor to mimic plant matter especially in tobacco. These 
compounds were found to be the major fractions in tobacco (Schiffman and Leffingwell 1981,

210 Forehand et al. 2000). Whereas lignin, pectin, ethyl cellulose, and tyrosine are well known

211 components of tobacco, glutamic acid has been found to be one of the major components in

212 burley tobacco (Sharma et al. 2006). Their estimated percentages in tobacco model sample

213 normalized to tyrosine were; Lig: EC: pectin: Tyr: Glutamic acid = 5:10:12:1:2, i.e tyrosine was

214 diluted by a factor of 30. The predominant products observed in this study were mainly

215 oxygenated products with hydrocarbon products as the minor products. Most of the products

216 were peaked at between 400 and $500{ }^{\circ} \mathrm{C}$ with the exception of phenols which peaked at about

$217500{ }^{\circ} \mathrm{C}$. Levoglucosan was exclusively the major pyrolysis product contributing nearly $50 \%$ of

218 the total products detected. Other major products included methyl alcohol and 5-(hydroxyl

219 methyl) furfural which were peaked at about 300 and $400{ }^{\circ} \mathrm{C}$, respectively. The minor products

220 detected included vinyl acetylene, propene and propane. At higher temperatures $\geq 400{ }^{\circ} \mathrm{C}$

221 benzene, toluene and a few aromatic hydrocarbons (indene, naphthalene and methyl

222 naphthalene) were detected in low quantities.

223 The phenolic compounds were detected surprisingly in much lower yields, Table 2.

224 While phenols are usually observed to form at lower temperatures $\left(<400{ }^{\circ} \mathrm{C}\right)$ during the

225 pyrolysis of individual biomass components such as lignin and tyrosine, phenolic compounds (cf.

226 Table 2) were observed to peak at higher temperatures $\left(>400{ }^{\circ} \mathrm{C}\right)$ when 5 component mixtures

227 were pyrolyzed together. This observation is similar to the pyrolysis of binary mixtures reported

228 in Fig. 2A, B and Fig. 3. It is clear from the data in Table 2 that the total yields of phenol+p-

229 cresol+o-cresol $\left(0.28 \%\right.$ at $\left.500{ }^{\circ} \mathrm{C}\right)$ dropped non proportionally to the dilution $(60.84 \%: 30 \sim$

$2302 \%$ ) i.e. instead of the expected $2 \%$ yield, $0.28 \%$ was found experimentally. 
Naturally a synergetic inhibition may occur in the pyrolysis mixture if we consider the 232 pathways of formation of phenol from tyrosine discussed elsewhere( 233 may form during pyrolysis via either direct decarboxylation and deamination (Fig. 5, left hand 234 side) widely documented in literature (Basiuk 1998, Douda and Basiuk 2000, $\underline{\text { Chiavari et al. }}$ $235 \underline{2001}$, Sharma et al. 2004, Li et al. 2008) or in modified, radical assisted degradation pathways 236 we discussed elsewhere (Kibet et al. 2013). In presence of tobacco biopolymers, (lignin or ethyl 237 cellulose) which have plenty of end $\mathrm{OH}$ groups, tyrosine may easily associate with the 238 biopolymer molecules through hydrogen bonding which may increase the energetic barrier for 239 phenol formation through decarboxylation/deamination or may cause a steric hindrance for 240 formation of phenol through radical degradation pathway, Fig. 5. As a result, the yields of 241 phenols (phenol and cresols) are expected to decrease synergistically with dilution. Note that 242 tyrosine (or similar compounds) may form intermolecular hydrogen bonding with complex 243 molecules in solution and solid phases which is well-known in literature (Huang et al. 1996, $\underline{\text { Pace }}$ 244 et al. 2001) (Kolev, 2007 \#5459). For instance, most tyrosine ${ }^{-} \mathrm{OH}$ groups contribute favorably 245 through the intermolecular hydrogen binding to protein stability (Pace et al. 2001).

246 The same phenomenon may be observed during oxidative co-pyrolysis of 247 biopolymer/tyrosine mixtures. It is known from our early research that $p$-tyramine is the major 248 product from tyrosine oxidative pyrolysis and that $p$-tyramine may be a source for formation of 249 phenol (Kibet et al. 2013), Fig. 5. Not only tyrosine, but also $p$-tyramine will be associated with 250 biopolymers through hydrogen bonding thereby strongly inhibiting the formation of phenol 251 during oxidative pyrolysis. The experimental fact that the reduction of phenol yields for EC/Tyr 252 mixture pyrolysis is larger than in case of Lig/Tyr (Fig. 4) may be explained by much high 253 concentration of the "end OH" groups in ethyl cellulose (43-48 \%) vs (18-33\%) in lignin (Lai et 
254 al. 2010). Based on the results obtained from this study, it is important to note that the use of 255 ethyl cellulose as a cigarette paper decreases the yields of phenols significantly.

\section{$256 \quad 4.0$ Conclusion}

257 This work has explored in detail the formation of phenolic compounds from the thermal 258 degradation of tobacco biomass materials such lignin, tyrosine, ethyl cellulose, sodium alginate, 259 and laminarin) as well as some mixtures (lignin/tyrosine, ethyl cellulose/tyrosine, sodium 260 alginate/tyrosine) that mimic plant matter. The main focus was directed towards the formation of 261 phenols (phenol, $o^{-}, m-, p$-cresols, catechol, hydroquinone, methoxy substituted phenols etc.) 262 from bio-polymeric mixtures with tyrosine as the greatest producer of phenolic compounds in 263 comparison to other biomass components. Moreover, the concept of dilution and synergic effect 264 as factors affecting the yields of pyrolysis products (phenolic compounds) in bio-polymeric 265 materials has been demonstrated in this study. Accordingly, a mechanistic explanation has been 266 proposed to elucidate this observation.

\section{Acknowledgement}

This work was supported by the R. J. Reynolds Tobacco Company and the Patrick F. 269 Taylor Chair Foundation. The authors thank Dr. Keith Cole, the Senior Staff Scientist at R.J. 270 Reynolds for valuable consultations. LK acknowledges a partial support from NSF Grant \# $271 \quad 1330311$. 


\section{References}

Agblevor, F. A., S. Beis, O. Mante, and N. Abdoulmoumine. 2010. Fractional Catalytic Pyrolysis of Hybrid Poplar Wood. Industrial \& Engineering Chemistry Research 49:3533-3538.

Anastasakis, K., A. B. Ross, and J. M. Jones. 2011. Pyrolysis behaviour of the main carbohydrates of brown macro-algae. Fuel 90:598-607.

Basiuk, V. A. 1998. Pyrolysis of valine and leucine at 500 degrees C: identification of lessvolatile products using gas chromatography Fourier transform infrared spectroscopy mass spectrometry. Journal of Analytical and Applied Pyrolysis 47:127-143.

Becidan, M., O. Skreiberg, and J. E. Hustad. 2007. NOx and N2O precursors (NH3 and HCN) in pyrolysis of biomass residues. Energy \& Fuels 21:1173-1180.

Berho, F., and R. Lesclaux. 1997. The phenoxy radical: UV spectrum and kinetics of gas-phase reactions with itself and with oxygen. Chemical Physics Letters 279:289-296.

Bolton, J. L., M. A. Trush, T. M. Penning, G. Dryhurst, and T. J. Monks. 2000. Role of quinones in toxicology. Chemical Research in Toxicology 13:135-160.

Chiavari, G., D. Fabbri, and S. Prati. 2001. Gas chromatographic-mass spectrometric analysis of products arising from pyrolysis of amino acids in the presence of hexamethyldisilazane. Journal of Chromatography A 922:235-241.

Cormier, S. A., S. Lomnicki, W. Backes, and B. Dellinger. 2006. Origin and health impacts of emissions of toxic by-products and fine particles from combustion and thermal treatment of hazardous wastes and materials. Environmental Health Perspectives 114:810-817.

D. Selassie, C., A. J. Shusterman, S. Kapur, R. P. Verma, L. Zhang, and C. Hansch. 1999. On the toxicity of phenols to fast growing cells. A QSAR model for a radical-based toxicity. Journal of the Chemical Society, Perkin Transactions 2:2729-2733. 
DeCaprio, A. P. 1999. The toxicology of hydroquinone - Relevance to occupational and environmental exposure. Critical Reviews in Toxicology 29:283-330.

Dellinger, B., W. A. Pryor, R. Cueto, G. Squadrito, and W. A. Deutsch. 2000. The role of combustion-generated radicals in the toxicity of PM2.5. Proceedings of the Combustion Institute 28:2675-2681.

Dellinger, B., W. A. Pryor, R. Cueto, G. L. Squadrito, V. Hegde, and W. A. Deutsch. 2001. Role of free radicals in the toxicity of airborne fine particulate matter. Chemical Research in Toxicology 14:1371-1377.

Douda, J., and V. A. Basiuk. 2000. Pyrolysis of amino acids: recovery of starting materials and yields of condensation products. Journal of Analytical and Applied Pyrolysis 56:113-121.

Evans, C. S., and B. Dellinger. 2005. Mechanisms of dioxin formation from the high-temperature oxidation of 2-chlorophenol. Environmental Science \& Technology 39:122-127.

Forehand, J. B., G. L. Dooly, and S. C. and Moldoveanu. 2000. Analysis of polycyclic aromatic hydrocarbons, phenols and aromatic amines in particulate phase cigarette smoke using simultaneous distillation and extraction as a sole sample clean-up step. Journal of Chromatography A 898:111-124.

Ghosh, A., A. Choudhury, A. Das, N. S. Chatterjee, T. Das, R. Chowdhury, K. Panda, R. Banerjee, and I. B. Chatterjee. 2012. Cigarette smoke induces p-benzoquinone-albumin adduct in blood serum: Implications on structure and ligand binding properties. Toxicology 292:78-89.

Guo, J. X., and D. G. Gray. 1994. Preparation, characterization, and mesophase formation of esters of ethylcellulose and methylcellulose Journal of Polymer Science Part a-Polymer Chemistry 32:889-896. 
Halliwell, B. B., H. E. Poulsen, and Eds. 2006. Cigarete Smoke and Oxidative Stress. SpringerVerlag Berlin Heidelberg.

Hansson, K. M., L. E. Amand, A. Habermann, and F. Winter. 2003. Pyrolysis of poly-L-leucine under combustion-like conditions. Fuel 82:653-660.

Hansson, K. M., J. Samuelsson, C. Tullin, and L. E. Amand. 2004. Formation of HNCO, HCN, and NH3 from the pyrolysis of bark and nitrogen-containing model compounds. Combustion and Flame 137:265-277.

Hirakawa, K., S. Oikawa, Y. Hiraku, I. Hirosawa, and S. Kawanishi. 2002. Catechol and hydroquinone have different redox properties responsible for their differential DNAdamaging ability. Chemical Research in Toxicology 15:76-82.

Huang, S. C., J. Huang, A. P. Kloek, D. E. Goldberg, and J. M. Friedman. 1996. Hydrogen bonding of tyrosine b10 to heme-bound oxygen in Ascaris hemoglobin - Direct evidence from UV resonance Raman spectroscopy. Journal of Biological Chemistry 271:958-962.

Khachatryan, L., Adounkpe, J., and Dellinger, B. 2008. Formation of Phenoxy and cyclopentadienyl radicals from the gas-phase pyrolysis of phenol. J.Phys.Chem., A 112:481-487.

Khachatryan, L., Asatryan R., Dellinger B.,. 2003. Development of an expanded and core kinetic model for the gas phase formation of dioxins from chlorinated phenols. Chemosphere, 52:695-708.

Kibet, J., L. Khachatryan, and B. Dellinger. 2012. Molecular Products and Radicals from Pyrolysis of Lignin. Environmental Science \& Technology 46:12994-13001.

Kibet, J. K., L. Khachatryan, and B. Dellinger. 2013. Molecular products from the pyrolysis and oxidative pyrolysis of tyrosine. Chemosphere 91:1026-1034. 
Lai, H. L., K. Pitt, and D. Q. M. Craig. 2010. Characterisation of the thermal properties of ethylcellulose using differential scanning and quasi-isothermal calorimetric approaches. International Journal of Pharmaceutics 386:178-184.

Lawrence J. Marnett, and a. A. L. Wilcox. 1988. The chemistry of lipid alkoxyl radicals and their role in metalamplified lipid peroxidation. Biochem. SOC. Symp. 61:65-72.

Li, J., Y. W. Liu, J. Y. Shi, Z. Y. Wang, L. Hu, X. Yang, and C. X. Wang. 2008. The investigation of thermal decomposition pathways of phenylalanine and tyrosine by TGFTIR. Thermochimica Acta 467:20-29.

Li, J., Z. Y. Wang, X. Yang, L. Hu, Y. W. Liu, and C. X. Wang. 2007. Evaluate the pyrolysis pathway of glycine and glycylglycine by TG-FTIR. Journal of Analytical and Applied Pyrolysis 80:247-253.

Maskos, Z., L. Khachatryan, and B. Dellinger. 2005. Precursors of radicals in tobacco smoke and the role of particulate matter in forming and stabilizing radicals. Energy \& Fuels 19:2466-2473.

Pace, C. N., G. Horn, E. J. Hebert, J. Bechert, K. Shaw, L. Urbanikova, J. M. Scholtz, and J. Sevcik. 2001. Tyrosine hydrogen bonds make a large contribution to protein stability. Journal of Molecular Biology 312:393-404.

Pryor, W. A., K. Stone, L. Y. Zang, and E. Bermudez. 1998. Fractionation of aqueous cigarette tar extracts: Fractions that contain the tar radical cause DNA damage. Chemical Research in Toxicology 11:441-448.

Pryor, W. A., Stone, K., Zang, L-Y., and Bermudez, E. 1998. Fractionation of Aqueous Cigarette Tar Extracts: Fractions that Contain the Tar Radical Cause DNA Damage. Chem.Res. Toxicol. 11:441-448. 
Ren, Q. Q., C. S. Zhao, X. P. Chen, L. B. Duan, Y. J. Li, and C. Y. Ma. 2011. NO(x) and N(2)O precursors $(\mathrm{NH}(3)$ and $\mathrm{HCN})$ from biomass pyrolysis: Co-pyrolysis of amino acids and cellulose, hemicellulose and lignin. Proceedings of the Combustion Institute 33:17151722.

Rioux, L. E., S. L. Turgeon, and M. Beaulieu. 2007. Characterization of polysaccharides extracted from brown seaweeds. Carbohydrate Polymers 69:530-537.

Rubey, W. A., and R. A. Grant. 1988. Design Aspects of a Modular Instrumentation System for Thermal Diagnostic StudiesReview of Scientific Instruments 59:265-269.

Schiffman, S. S., and J. C. Leffingwell. 1981. Basic Chemical Constituents of Tobacco Leaf and Differences among Tobacco Types. . Tobacco: Production. Chemistry and Technology.

Sharma, R. K., W. G. Chan, and M. R. Hajaligol. 2006. Product compositions from pyrolysis of some aliphatic alpha-amino acids. Journal of Analytical and Applied Pyrolysis 75:69-81.

Sharma, R. K., W. G. Chan, J. Wang, B. E. Waymack, J. B. Wooten, J. I. Seeman, and M. R. Hajaligol. 2004. On the role of peptides in the pyrolysis of amino acids. Journal of Analytical and Applied Pyrolysis 72:153-163.

Smith, C. J., and C. Hansch. 2000. The relative toxicity of compounds in mainstream cigarette smoke condensate. Food and Chemical Toxicology 38:637-646.

Squadrito, G. L., R. Cueto, B. Dellinger, and W. A. Pryor. 2001. Quinoid redox cycling as a mechanism for sustained free radical generation by inhaled airborne particulate matter. Free Radical Biology and Medicine 31:1132-1138.

Talhout, R., T. Schulz, E. Florek, J. van Benthem, P. Wester, and A. Opperhuizen. 2011. Hazardous Compounds in Tobacco Smoke. International Journal of Environmental Research and Public Health 8:613-628. 
390 Wiater, I., J. G. P. Born, and R. Louw. 2000. Products, rates, and mechanism of the gas-phase condensation of phenoxy radicals between 500-840 K. Eur.J.Org.Chem.:921-928.

392

393 


\section{FIGURES}

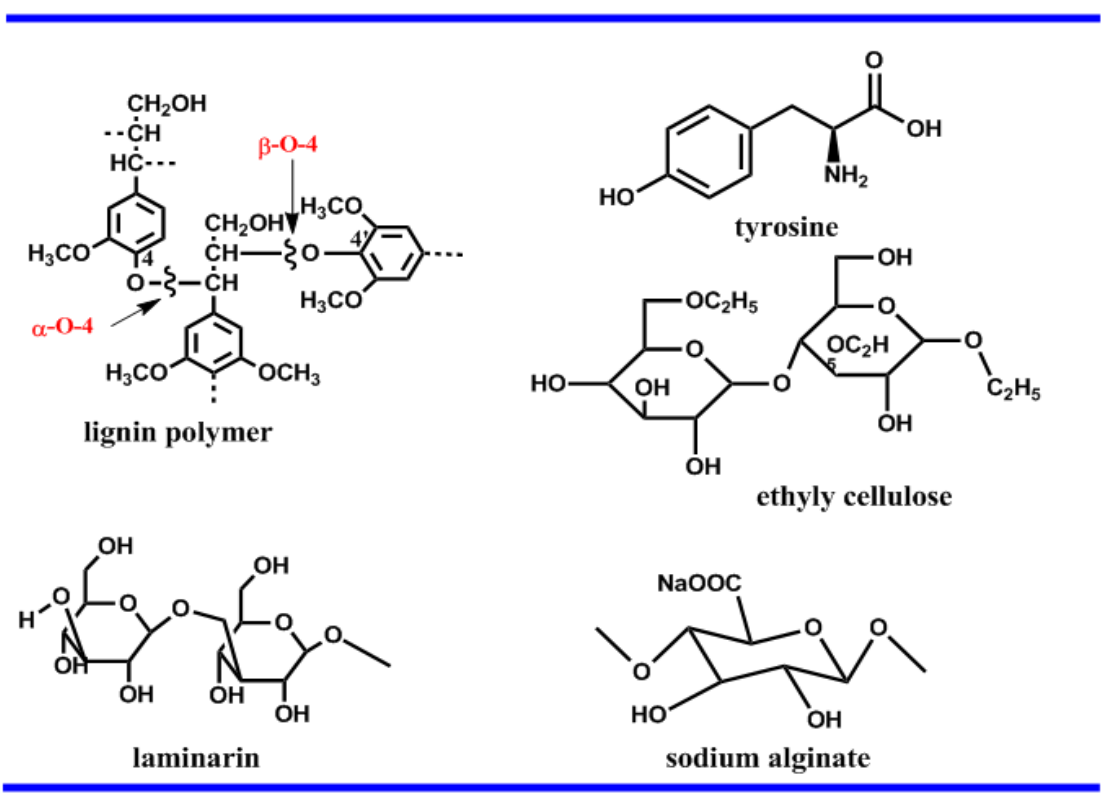

395 Fig. 1. Tobacco Biomass materials investigated in this study 

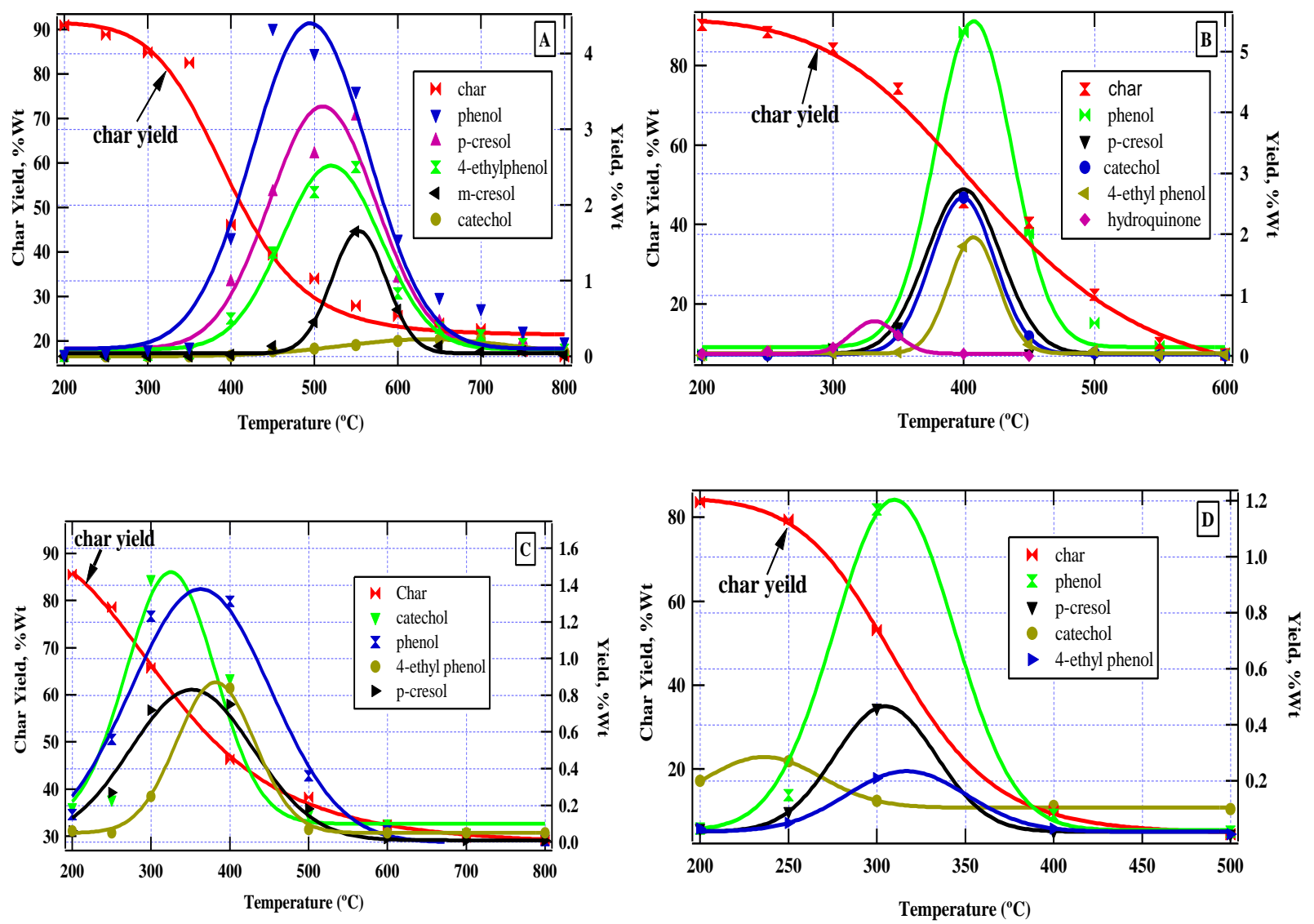

Fig. 2. Co-pyrolysis of lignin/tyrosine mixture (A and $\mathbf{B}$ ) in $\mathrm{N}_{2}$ and $4 \% \mathrm{O}_{2}$ in $\mathrm{N}_{2}$ respectively, and pyrolysis of lignin ( $C$ and D) in $\mathrm{N}_{2}$ and $4 \% \mathrm{O}_{2}$ in $\mathrm{N}_{2}$, respectively. 

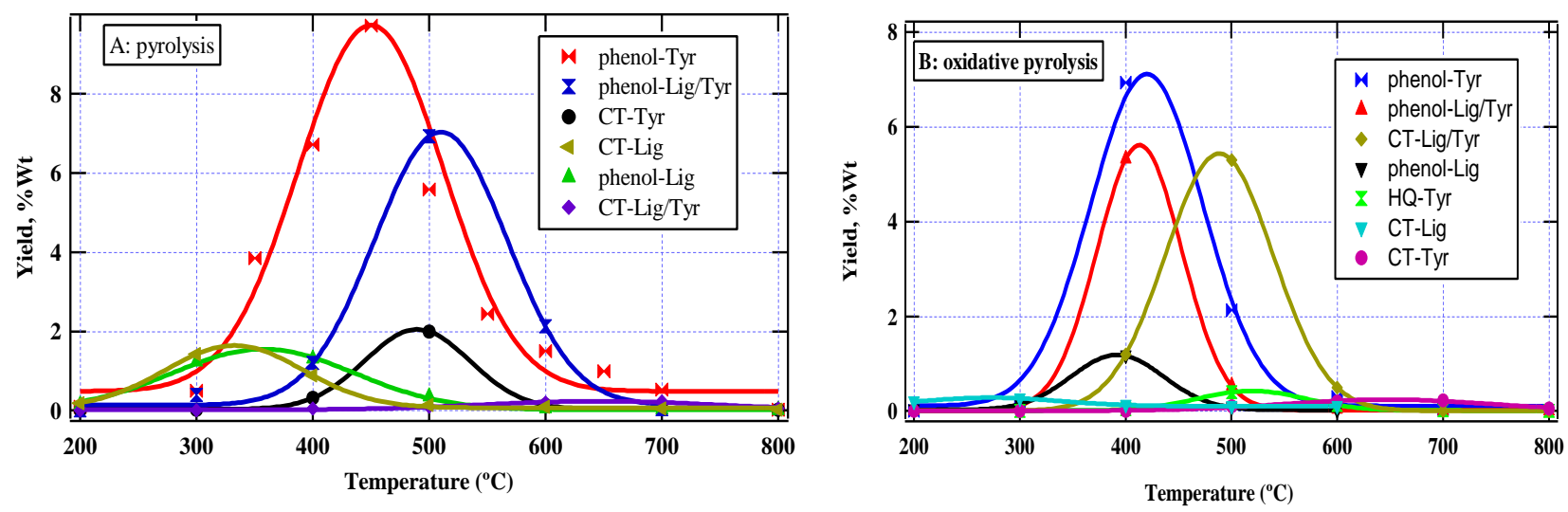

Fig. 3. Comparison of phenols (in wt \%) from pyrolysis (A) / oxidative pyrolysis (B) of lignin, tyrosine, and Lig/Tyr mixture.

401

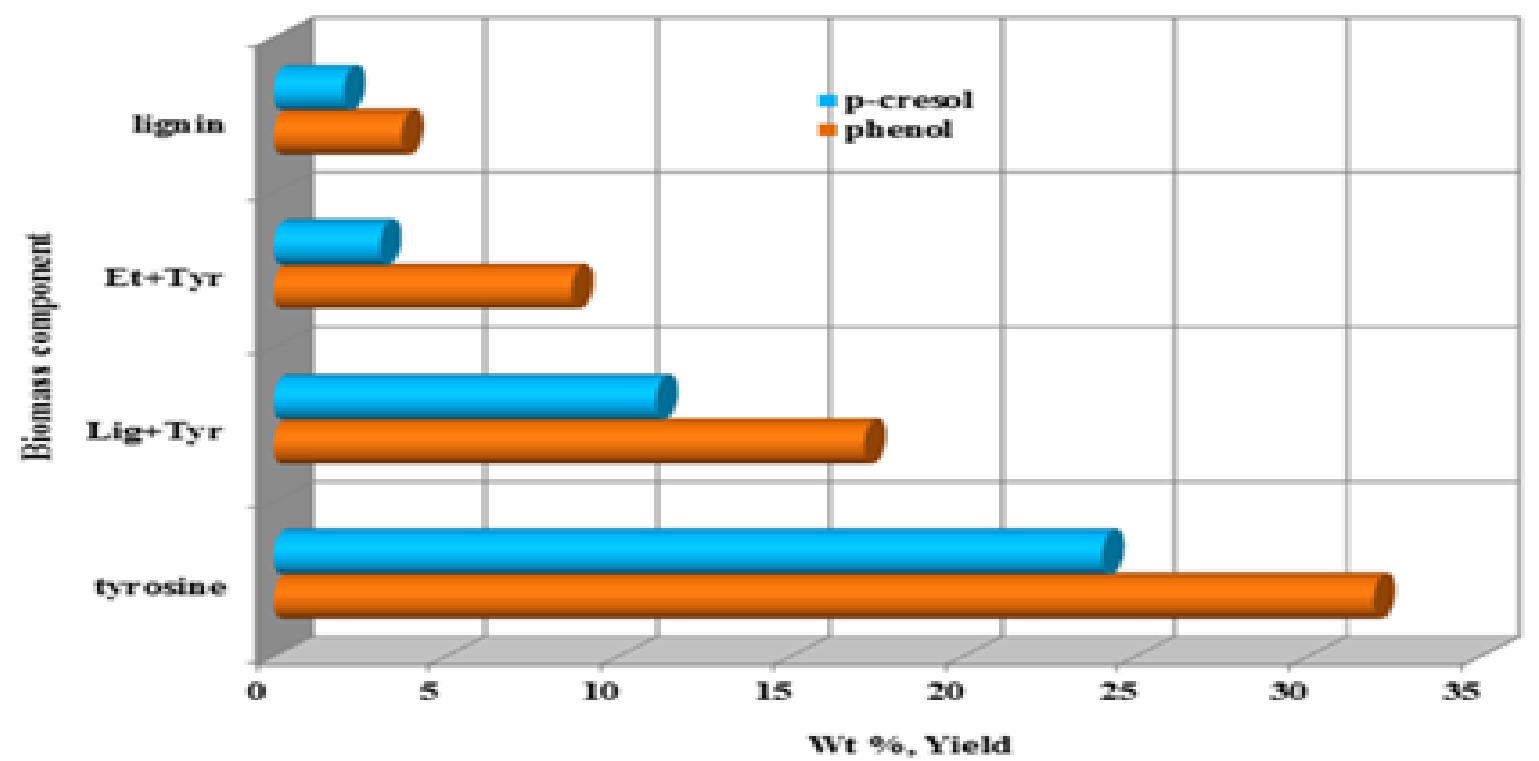

403 Fig. 4. Total wt \% yields of phenol (brown line) and $p$-cresol (blue line) from pyrolysis of various biomass components in the temperature region from $200{ }^{\circ} \mathrm{C}$ to $900{ }^{\circ} \mathrm{C}$. 


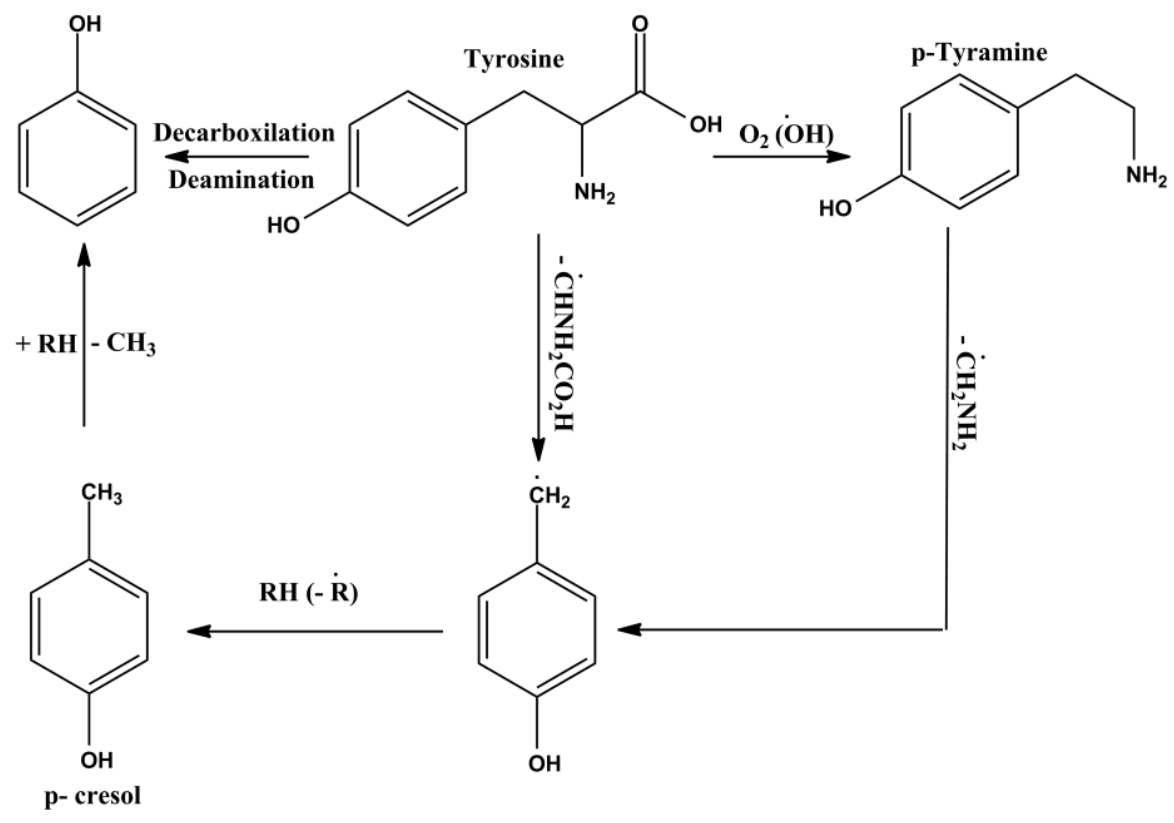

Fig. 5. Possible pathways for formation of phenol from pyrolysis of tyrosine through decarboxylation/deamination, radical assisted degradation (left hand side) and oxidative pyrolysis through participation of oxygen and hydroxyl radicals, right hand side. 


\begin{tabular}{lcccccccc}
\hline Compound & \multicolumn{4}{c}{ Pyrolysis (Yield in Wt \%) } & \multicolumn{3}{c}{ Oxidative pyrolysis (Yield in Wt \%) } \\
& Lignin & Tyrosine & Lig/Tyr & EC/Tyr & Lignin & Tyrosine & Lig/Tyr & $\begin{array}{c}\text { EC/T } \\
\text { yr }\end{array}$ \\
\hline phenol & 3.71 & 31.89 & 17.12 & 8.64 & 1.45 & 16.36 & 8.70 & 0.90 \\
$p$-cresol & 2.02 & 24.03 & 11.08 & 3.07 & 0.61 & 10.34 & 3.45 & 0.65 \\
$o$-cresol & nd & 4.92 & nd & 0.65 & nd & 2.55 & nd & 0.46 \\
catechol & 3.07 & nd & 1.14 & 0.46 & nd & 0.81 & nd & nd \\
ethyl phenol & 1.87 & nd & 8.39 & 2.32 & 0.33 & nd & 0.33 & 0.47 \\
hydroquinone & nd & 0.64 & 0.06 & 3.10 & nd & nd & 0.65 & nd \\
$p$-tyramine & - & 1.61 & 2.45 & 2.30 & - & 6.14 & nd & 0.23 \\
guaiacol & 2.68 & - & 5.57 & nd & 1.30 & - & 2.45 & nd \\
syringol & 8.28 & - & 7.39 & nd & 2.32 & - & 3.26 & nd \\
4-vinyl guaiacol & 5.07 & - & 3.44 & nd & 1.69 & - & 4.07 & nd \\
eugenol & 4.39 & - & 5.42 & nd & 1.44 & - & 0.36 & nd \\
3-methoxy catechol & 2.27 & - & 1.63 & nd & 1.11 & - & 0.87 & nd \\
\hline
\end{tabular}

427 Table 2. Quantified yields (Wt \%) of Phenolic Compounds from Fractional Co-Pyrolysis of Lignin,

428 Cellulose, Pectin, Tyrosine, and Glutamic Acid Mixture at different Temperatures in $\mathrm{N}_{2}$ at 1 atm.

\begin{tabular}{lllllllll}
\hline \multirow{2}{*}{ Quantified Yields } & \multicolumn{7}{c}{ Pyrolysis Temperature $\left({ }^{\circ} \mathrm{C}\right)$} \\
\cline { 2 - 9 } phenol & 200 & 300 & 350 & 400 & 450 & 500 & 550 & 600 \\
o-cresol & 0.00 & 0.00 & 0.00 & 0.01 & 0.01 & 0.12 & 0.02 & 0.01 \\
p-cresol & 0.00 & 0.00 & 0.00 & 0.01 & 0.01 & 0.05 & 0.01 & 0.01 \\
2,3-dimethyl phenol & 0.00 & 0.00 & 0.00 & 0.01 & 0.02 & 0.11 & 0.02 & 0.01 \\
p-ethyl phenol & 0.00 & 0.00 & 0.00 & 0.01 & 0.02 & 0.05 & 0.02 & 0.01 \\
catechol & 0.00 & 0.00 & 0.00 & 0.01 & 0.03 & 0.08 & 0.03 & 0.02 \\
& 0.00 & 0.00 & 0.00 & 0.01 & 0.03 & 0.04 & 0.02 & 0.01 \\
Wt \% Total & - & - & - & $\mathbf{0 . 0 6}$ & $\mathbf{0 . 1 2}$ & $\mathbf{0 . 4 5}$ & $\mathbf{0 . 1 2}$ & $\mathbf{0 . 0 7}$ \\
\hline
\end{tabular}

